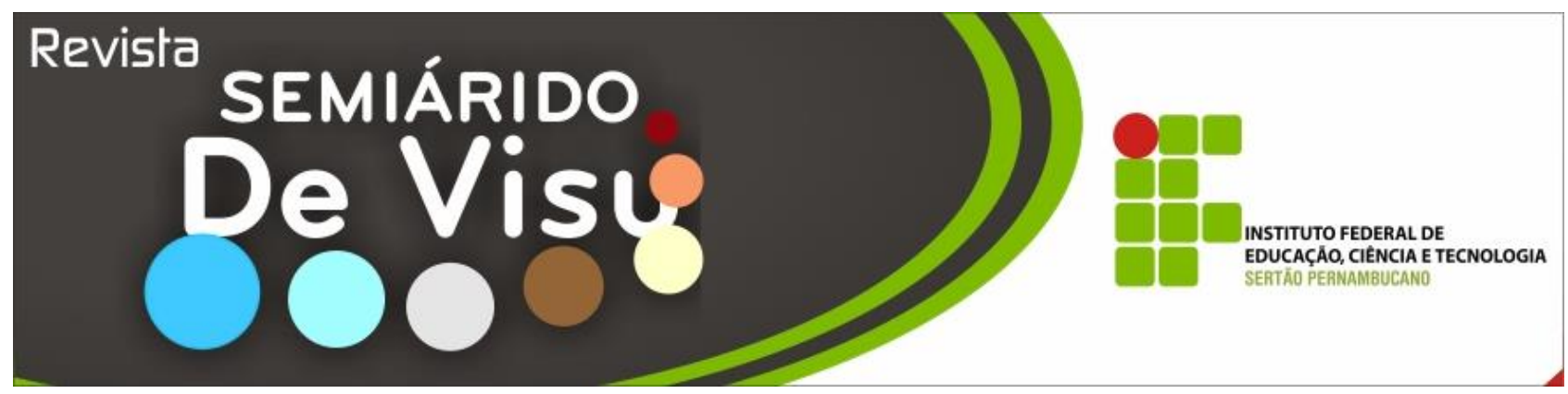

\title{
Avaliação da qualidade de méis de abelhas Apis mellifera comercializados no município de Ouricuri-PE
}

\author{
Társio Thiago Lopes Alves ${ }^{1}$, Rosangela Maria Pereira ${ }^{2}$, Janeanne Nascimento Silva ${ }^{3}$, Iris Maria \\ Silva $^{4}$, Josias Lopes Valgão ${ }^{5}$, Sergio Eduardo de Holanda Alencar ${ }^{6}$, Allexandre Emerson Silva \\ Holanda $^{7}$, Juliana Cantalino Santos ${ }^{8}$ \\ 1, 2 3, 4, 5, 6, 7, 8 Instituto Federal do Sertão Pernambucano - campus Ouricuri. Ouricuri - Pernambuco - Brasil.
}

\begin{abstract}
RESUMO: Considerado um dos alimentos mais puros da natureza, o mel é apreciado por seu sabor característico e considerável valor nutritivo, seu preço é relativamente alto, o que incentiva muitas vezes a sua adulteração. Objetivouse avaliar a qualidade dos méis comercializados em Ouricuri - PE. Foram adquiridas 5 amostras com cerca de $500 \mathrm{ml}$ no comércio em cada meio de comercialização. Previamente, observou-se os tipos e higienização das embalagens, bem como a presença e informações dos rótulos. Posteriormente, realizou-se as análises microbiológicas e físico-químicas. Os dados foram analisados por meio de análise de variância e as médias comparadas pelo teste de Tukey (5\%), utilizando Delineamento Inteiramente Casualizado, com três tratamentos, com cinco repetições. Constatou-se que as amostras estavam isentas de microorganismos, 53,33\% das amostras apresentaram cor âmbar e algumas características estavam com valores acima do permitido pela legislação. Observou-se que os méis oriundos de feira livres tiveram $62,5 \%$ dos parâmetros de embalagens em não conformidade, supermercados $25 \%$ e apicultores $75 \%$. Apenas as amostras de supermercados tinham rótulos, entretanto, fora de conformidade. Conclui-se que mesmo o mel sendo resistente à microorganismos, deve-se ter cuidados com BPF's (Boas Práticas de Fabricação), desde o campo até a unidade de extração, a fim de que o mesmo não se torne impróprio ao consumo.
\end{abstract}

Palavras-chave: Abelha Africanizada, Comercialização e Controle de Qualidade.

\section{Quality assessment of honey from Apis mellifera sold in Ouricuri town, Pernambuco State}

\begin{abstract}
Considered one of the purest food of nature, honey is appreciated for its characteristic taste and considerable nutritional value, its price is relatively high, which often encourages its adulteration. This study aimed to assess the quality of honeys sold in Ouricuri town, Pernambuco State. Five samples with about $500 \mathrm{ml}$ were acquired in trade for each way of marketing. First, it was observed types of packaging and sanitizing, as well as label presence and information. Later, microbiological and physico-chemical analyzes were performed. Data were analyzed by ANOVA and means were compared by Tukey test (5\%), using Completely randomized design with three treatments with five replications. It was found that samples were free from microorganisms, and $53.33 \%$ of the samples showed amber color, but some features were with values above those permitted by law. It was observed that the honey from fair had $62.5 \%$ of the parameters in non-conformity, and supermarkets had $25 \%$, and beekeepers $75 \%$. Only samples from supermarkets had labels, however, they were out of compliance. It is concluded that even honey being resistant to microorganisms, care must be taken to GMP (Good Manufacturing Practices) from the field to the extraction unit in order to honey does not become improper for consumption.
\end{abstract}

keywords: Africanized honey bee, Marketing and Quality Control. 
Introdução

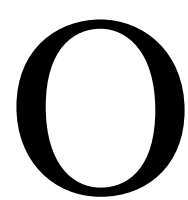

mel, produto natural elaborado por abelhas a partir do néctar das flores, é coletado e transformado por elas por meio de dois processos básicos: um físico, evaporação da água e outro químico, adição de enzimas. Ele é um dos produtos da colméia mais usados, tanto in natura quanto em diversas formas industrializadas (Komatsu et al., 2002). Sendo considerado um dos alimentos mais puros da natureza, apreciado por seu sabor característico e considerável valor nutritivo, seu preço é relativamente alto, o que incentiva muitas vezes a sua adulteração (Araújo, 2006).

As características dos méis dependem de sua origem, sendo influenciadas pelas condições climáticas e pela matéria-prima utilizada pelas abelhas. Essa dependência se reflete na cor, no sabor, no odor, na viscosidade e nas características químicas e físico-químicas dos méis, cuja diversidade é tão ampla quanto às condições em que o mesmo é elaborado. Assim sendo, a caracterização de méis produzidos em determinadas condições locais definem a sua qualidade no mercado, estabelecendo as características peculiares inerentes à sua origem, possibilitando sua padronização, como também fornecendo informações para garantir controle de qualidade do produto, detectando eventuais alterações. Análises químicas, físico-químicas e microbiológicas de méis permitem instrumentalizar os produtores e a indústria do mel com dados que permitam o suprimento do mercado com produtos que atendam a demandas específicas (Silva, 2005).

Muitos autores têm avaliado a qualidade do mel comercializado no Brasil (Araújo et al., 2006; Leal et al., 2001; Rodrigues et al., 2005; Sodré et al., 2007). Em muitos destes estudos, tem-se verificado que um número considerável de amostras não atende as especificações das normas brasileiras (Brasil, 2000) e internacionais (Codex Alimentarius, 2001).

Objetivou-se, portanto, avaliar a qualidade dos méis de Apis mellifera comercializados no Município de Ouricuri, PE.

\section{Material e métodos}

Foram adquiridas cinco (05) amostras de méis de abelha Apis mellifera com cerca de $700 \mathrm{~g}(500 \mathrm{ml})$ por amostra no comércio local do Município de Ouricuri-PE para cada meio de comercialização (feiras livres, redes de supermercados e apicultores). Durante a coleta das amostras, foram observadas tipos das embalagens, bem como a presença $e$ informações dos rótulos. Posteriormente, realizou-se as análises microbiológicas e físicoquímicas.

As análises microbiológicas de bolores e leveduras, coliformes fecais e termotolerantes foram realizadas de acordo com o descrito na Instrução Normativa n 62, de 26 de agosto de 2003, que oficializa os métodos de análises microbiológicas para produtos de origem animal e se baseia na verificação da capacidade dos microrganismos se desenvolverem em meios de cultura com pH próximo a 3,5. Para bolores e leveduras foi utilizado o método de plaqueamento por "pour-plate", com incubação a $35^{\circ} \mathrm{C}$ por 48 horas e os resultados expressos em UFC/g e para contagem de coliformes fecais e termotolerantes foi o método do Número Mais Provável (NMP). Por esta técnica, pode-se obter informações sobre a população presuntiva de coliformes (teste presuntivo) sobre a população real de coliformes (teste confirmativo) e sobre a população de coliformes de origem fecal (coliformes fecais).

Para a realização das análises físicoquímicas utilizou-se as metodologias recomendadas pelo Ministério da Agricultura e do Abastecimento - Instrução Normativa (Brasil, 2000) e de acordo com as normas analíticas do Instituto Adolfo Lutz (IAL, 2008).

Os parâmetros avaliados em triplicada foram cor, determinada em espectrofotômetro modelo QUIMIS [U2M] a 560nm, em célula de $1 \mathrm{~cm}$, usando como branco a glicerina pura. $\mathrm{O}$ resultado foi dado em absorbância e convertido através da Escala de Pfund para classificação da coloração e a umidade, determinada pelo índice de refração do mel a $20^{\circ} \mathrm{C}$, que é 
convertido para umidade através da tabela de referência de Chataway.

Os sólidos solúveis presentes nos méis foram determinados por leitura direta da amostra em refratômetro de bancada do tipo Abbe; $\mathrm{pH}$, determinado segundo o método eletrométrico com auxílio de pHmetro calibrado e a acidez, utilizando titulação simples do mel com solução de $\mathrm{NaOH}$ a $0,05 \mathrm{~N}$ até atingir $\mathrm{pH}$ de 8,5.

O teor de cinzas foi realizado através da incineração das amostras em mufla aquecida a $600^{\circ} \mathrm{C}$; a prova de Lund, determinada pela precipitação dos albuminóides do mel pelo ácido tânico sendo considerada negativa para adulteração quando o precipitado variar de 0,6 a 3,0 mL no fundo da proveta, após 24 horas de descanso e sólidos insolúveis, determinado por gravimetria.

$\mathrm{Na}$ determinação quantitativa de hidroximetilfurfural (HMF), utilizou-se o ácido barbitúrico, na qual o princípio da análise se baseia que em meio ácido o ácido barbitúrico condensa-se com o hidroximetilfurfural formando um composto de coloração vermelha (Lanara, 1981). A leitura foi feita em espectrofotômetro baseado na absorbância do HMF a $550 \mathrm{~nm}$; prova de fiehe qualitativa, consiste no fato da resorcina na presença de glicose comercial ou de mel superaquecido, aparecerá uma coloração vermelha intensa após 5 a 10 minutos, indicando a fraude.

Os açúcares redutores foram quantificados por titulometria pelo método de Lane-Eynon e sacarose aparente determinada pela diferença entre os glicídeos totais e redutores; a diastase foi determinada pelo método qualitativo adotado por Brasil (2000), no qual se fundamenta na hidrólise do amido pela ação das amilases existentes no mel. Na presença de fermentos diastásicos (mel natural) aparecerá uma coloração verde-oliva ou castanha. A prova de lugol foi realizada utilizando o iodo e iodeto de potássio (lugol), conforme metodologia indicada pelo Instituto
Adolfo Lutz (2008). Considerando positiva quando a coloração final for violeta ou azul. $\mathrm{Na}$ presença de glicose comercial ou xaropes de açúcar, a solução ficaria colorida de marromavermelhada a azul.

Os dados foram analisados por meio de análise de variância e as médias comparadas pelo teste de Tukey (5\%). O delineamento utilizado foi o inteiramente casualizado, com três tratamentos (locais de comercialização) e cinco repetições.

\section{Resultados e discussão}

Das 15 amostras de méis analisadas, sendo cinco para cada meio de comercialização, apenas três (20\%) comercializadas em redes de supermercados, apresentaram embalagens plásticas próprias para armazenamento de mel, contendo rótulo com informações sobre origem, peso, data de colheita e validade, sendo que $12(80 \%)$ eram envasadas em embalagens reutilizadas não apropriadas para o produto, tais como garrafas tipo pet para refrigerantes $(60 \%)$ e garrafas de vidro para cachaça $(20 \%)$.

$\mathrm{O}$ uso de embalagens reutilizadas, impróprias para o acondicionamento do mel, oferece perigo devido à contaminação cruzada do produto por microorganismos patogênicos. Segundo o Regulamento Técnico para Fixação de Identidade e Qualidade do Mel, o mel pode apresentar-se a granel ou fracionado, devendo ser acondicionado em embalagem apta para alimento, adequada às condições previstas de armazenamento e que confira proteção adequada contra contaminação. Além disso, não deve conter substâncias estranhas, de qualquer natureza, tais como insetos, larvas, grãos de areia e outros (Brasil, 2000).

Os resultados das análises microbiológicas dos méis comercializados no Município de Ouricuri-PE, estão apresentados na tabela 01 .

Tabela 1 - Resultados das análises microbiológicas de méis comercializados no município de

Ouricuri-PE, 2014.

\begin{tabular}{cccc}
\hline Comercialização & Amostra & Bolores e Leveduras (UFC/g) & Coliformes Fecais e Termotolerantes (NMP/g) \\
\hline Feira Livre & 1 & Ausente & $<3$
\end{tabular}


(ALVES et al., 2015)

\begin{tabular}{llll} 
Feira Livre & 2 & Ausente & $<3$ \\
Feira Livre & 3 & Ausente & $<3$ \\
Feira Livre & 4 & Ausente & $<3$ \\
Feira Livre & 5 & Ausente & $<3$ \\
\hline Supermercado & & $<3$ \\
Supermercado & 1 & Ausente & $<3$ \\
Supermercado & 2 & Ausente & $<3$ \\
Supermercado & 3 & Ausente & $<3$ \\
Supermercado & 4 & Ausente & $<3$ \\
\hline & 5 & Ausente & $<3$ \\
\hline Produtor & & $<3$ \\
Produtor & 1 & Ausente & $<3$ \\
Produtor & 2 & Ausente & $<3$ \\
Produtor & 3 & Ausente & $<3$ \\
Produtor & 4 & Ausente & $<$ \\
\hline
\end{tabular}

Observa-se que para todas as amostras, não houve presença de microorganismos patógenos e/ou estavam dentro dos valores permitidos pela legislação brasileira. Esses resultados são semelhantes aos obtidos por Silva et al. (2008), Alves et al. (2009), Lieven et al. (2009), Schlabitz et al. (2010) e Santos et al. (2011a), que também não detectaram microorganismos patógenos em méis de abelhas melíferas provenientes de diversas cidades brasileiras.

$\mathrm{Na}$ tabela 02, estão apresentados os resultados das análises físico-químicas dos méis comercializados no Município de Ouricuri-PE.

Tabela 02 - Resultados dos parâmetros físico-químicas de umidade, acidez, HMF, Prova de Fiehe, Açúcares redutores e sacarose aparente dos méis comercializados no município de Ouricuri-PE, 2014.

\begin{tabular}{|c|c|c|c|c|c|c|c|}
\hline Comercialização & Amostra & Umidade (\%) & Acidez (m.e.q/Kg) & HMF (mg/Kg) & Fiehe & Aç. Redutores (\%) & Sacarose (\%) \\
\hline Feira Livre & 1 & 16,00 & 39,33 & 90,83 & positivo & 67,89 & 7,14 \\
\hline Feira Livre & 2 & 16,83 & 35,67 & 39,73 & negativo & 61,25 & 8,74 \\
\hline Feira Livre & 3 & 17,87 & 37,67 & 4,00 & negativo & 63,48 & 2,66 \\
\hline Feira Livre & 4 & 16,90 & 38,67 & 54,01 & negativo & 71,54 & 1,12 \\
\hline Feira Livre & 5 & 17,47 & 36,33 & 14,01 & negativo & 71,85 & 1,99 \\
\hline Média & & $17,01 a$ & $37,53 a b$ & $40,52 a$ & & $67,20 a$ & $4,33 b$ \\
\hline Supermercado & 1 & 16,67 & 33,67 & 10,95 & negativo & 69,44 & 3,58 \\
\hline Supermercado & 2 & 17,20 & 17,67 & 35,72 & negativo & 73,13 & 1,29 \\
\hline Supermercado & 3 & 17,40 & 18,00 & 35,25 & negativo & 67,10 & 3,69 \\
\hline Supermercado & 4 & 16,87 & 23,33 & 16,01 & negativo & 65,62 & 4,01 \\
\hline Supermercado & 5 & 17,20 & 35,33 & 26,23 & negativo & 71,33 & 5,54 \\
\hline Média & & $17,07 a$ & $25,60 \mathrm{~b}$ & $24,83 a$ & negativo & $69,32 a$ & $3,62 b$ \\
\hline Produtor & 1 & 16,10 & 31,33 & 25,61 & negativo & 64,85 & 5,29 \\
\hline Produtor & 2 & 17,50 & 40,67 & 16,61 & negativo & 66,45 & 6,45 \\
\hline Produtor & 3 & 20,90 & 55,67 & 4,12 & negativo & 68,36 & 12,72 \\
\hline Produtor & 4 & 19,00 & 50,67 & 53,10 & negativo & 67,27 & 10,89 \\
\hline Produtor & 5 & 18,33 & 40,33 & 35,17 & negativo & 70,62 & 10,78 \\
\hline Média & & $18,37 a$ & $43,73 a$ & $26,92 a$ & negativo & $67,51 a$ & $9,23 a$ \\
\hline
\end{tabular}

Médias seguidas da mesma letra, nas colunas, não diferem estatisticamente entre si, pelo teste de Tukey ao nível de $5 \%$ de probabilidade. 
De acordo com a Tabela 02, verificou-se que em relação ao teor de umidade todos os méis comercializados obtiveram o valor médio dentro do limite exigido pela legislação, não havendo diferença estatística entre elas e que apenas uma das cinco amostras comercializadas por produtores apresentou umidade superior a $20 \%$. O teor médio encontrado foi de $17,48 \%$, com variação de 17,01 a $18,37 \%$. A umidade é uma das características mais importantes, por influenciar na viscosidade, peso específico, maturidade, cristalização, sabor, conservação e palatabilidade do mel. Santos et al. (2011b) encontraram em méis comercializados em Russas, CE, teores de umidade variando de 16,92 a $22,00 \%$ com média de $19,06 \%$, valores próximos aos encontrados na pesquisa.

Em relação ao parâmetro de acidez, observou-se que todos os méis comercializados obtiveram o valor médio dentro do limite exigido pela legislação, havendo diferença estatística entre elas, entretanto, uma amostra comercializada por produtores foi reprovada com valor de acidez superior ao permitido pela legislação, que é de no máximo $50 \mathrm{~m} . \mathrm{Eq} . / \mathrm{kg}$ (Brasil, 2000). O valor médio encontrado foi de $37,53 \mathrm{~m} . \mathrm{Eq} . / \mathrm{kg}$, para os méis comercializados em feiras livres, 25,60 m.Eq./kg para méis dos supermercados e 43,73 m.Eq./kg para méis comercializados pelos produtores. Santos et al. (2009) verificaram que quatro amostras de méis comercializadas na região do Vale do Jaguaribe, CE, apresentaram valores de acidez acima do permitido.

$\begin{array}{cccc}\text { Para os } & \text { valores de } & \text { HMF } \\ \text { (hidroximetilfurfural) } & \text { todos } & \text { os } & \text { méis }\end{array}$ comercializados obtiveram o valor médio dentro do limite exigido pela legislação, não havendo diferença estatística entre elas, porém, das cinco amostras dos méis comercializados em feiras livres, uma apresentou resultado acima do limite permitido pela legislação que é de no máximo $60 \mathrm{mg} / \mathrm{Kg}$ (Brasil, 2000). Os méis comercializadas em supermercados e produtores apresentaram médias de 24,83 e $26,92 \mathrm{mg} / \mathrm{Kg}$, respectivamente, estando dentro dos limites preconizados. Santos et al. (2010) também encontraram índice de reprovação de uma amostra analisada nos méis comercializados em Tabuleiro do Norte, CE. O
HMF no mel é um indicador de aquecimento, armazenamento e adulteração com açúcar invertido. Segundo Dayrell e Vital (1991), em países de clima tropical, as amostras de méis costumam apresentar elevado teor de HMF em função do clima quente, sendo a quantificação deste parâmetro fundamental para a verificação da qualidade do produto.

A reação de Fiehe é uma análise que indica a presença de substâncias produzidas durante o superaquecimento do mel ou a adição de xaropes de açúcares. Desta forma, quando o resultado for positivo, indica a alteração e/ou adulteração do produto. Das amostras analisadas apenas uma comercializada em feira livre apresentou resultado positivo para reação de Fiehe. A legislação vigente não menciona esta análise como obrigatória.

Para açúcares redutores, todos os valores médios encontraram-se dentro dos parâmetros exigidos pela legislação nos três locais de comercialização, não apresentando diferença estatística. Os resultados mostram variação de $61,25 \%$ a $71,85 \%$ para os méis comercializados em feiras livres, $65,62 \%$ a $73,13 \%$ para os comercializados em supermercados e $64,85 \%$ a 70,62 para os méis de produtores. A legislação estabelece teor mínimo de $65 \%$, sendo que o resultado médio obtido foi de $67,20 \%, 69,32 \%$ e $67,51 \%$, respectivamente, portanto, dentro dos parâmetros exigidos. Santos et al. (2011b) encontraram em todas as amostras de méis comercializadas em Russas, CE, valores acima do estabelecido pela legislação variando de 74,23 a $80,18 \%$. De acordo com Moreira e De Maria (2001), os teores de frutose e glicose são extremamente importantes para 0 estabelecimento de uma série de características do mel, como por exemplo, a granulação.

A porcentagem de sacarose aparente apresentou valor médio acima do preconizado pela legislação nos méis comercializados por produtores, diferindo dos demais locais de comercialização. Os valores variaram de 1,12 a $8,74 \%$ com média de $4,33 \%$ para comercialização em feiras livres, 1,29 a 5,54\% com média de $3,62 \%$ para os comercializados em supermercados e 5,29 a 12,72\% com média de 9,23\% para mel de produtor. Dias et al. 
(2009) também encontrou em méis de sacarose aparente acima do estabelecido comercializados em diferentes pontos de venda no Município de Londrina, PR, valores médios pela legislação.

Tabela 03 - Resultados dos parâmetros de cor, sólidos insolúveis em água, cinzas, lund, diastase e lugol dos méis comercializados no município de Ouricuri-PE, 2014.

\begin{tabular}{|c|c|c|c|c|c|c|c|}
\hline Comercialização & Amostra & Cor & In solúve is (\%) & Cinzas (\%) & Lund & Diastase & Lugol \\
\hline Feira Livre & 1 & âmbar & 0,65 & 0,20 & positivo & positiva & positivo \\
\hline Feira Livre & 2 & âmbar & 0,91 & 0,61 & positivo & positiva & negativo \\
\hline Feira Livre & 3 & âmbar claro & 1,17 & 0,81 & positivo & positiva & negativo \\
\hline Feira Livre & 4 & âmbar & 0,84 & 0,60 & positivo & positiva & negativo \\
\hline Feira Livre & 5 & âmbar claro & 0,88 & 0,52 & positivo & positiva & negativo \\
\hline Média & & & $0,89 a$ & $0,55 a$ & positivo & positiva & \\
\hline Supermercado & 1 & âmbar & 0,21 & 0,20 & positivo & positiva & negativo \\
\hline Supermercado & 2 & âmbar claro & 0,11 & 0,23 & positivo & positiva & negativo \\
\hline Supermercado & 3 & âmbar claro & 0,98 & 0,78 & positivo & positiva & negativo \\
\hline Supermercado & 4 & extra âmbar claro & 0,55 & 0,45 & positivo & positiva & negativo \\
\hline Supermercado & 5 & âmbar & 0,67 & 0,65 & positivo & positiva & negativo \\
\hline Média & & & $0,51 a$ & $0,46 a$ & positivo & positiva & negativo \\
\hline Produtor & 1 & âmbar & 0,91 & 0,55 & positivo & positiva & negativo \\
\hline Produtor & 2 & âmbar & 0,37 & 0,27 & positivo & positiva & negativo \\
\hline Produtor & 3 & âmbar & 1,05 & 0,81 & positivo & positiva & negativo \\
\hline Produtor & 4 & âmbar claro & 0,15 & 0,24 & positivo & positiva & negativo \\
\hline Produtor & 5 & âmbar claro & 0,75 & 0,92 & positivo & positiva & negativo \\
\hline Média & & & $0,64 a$ & $0,56 a$ & positivo & positiva & negativo \\
\hline
\end{tabular}

Os resultados mostram que $53,33 \%$ das amostras analisadas apresentaram coloração âmbar. Quanto à análise de sólidos insolúveis em água, todos os valores médios de todos os locais de comercialização encontram-se fora dos limites estabelecidos, apresentando valores superiores a 0,1 g/100g, que é o máximo permitido pela legislação brasileira (Brasil, 2000), não diferindo entre elas. O valor médio de insolúveis encontrado foi de 0,65 a $1,17 \%$ para os méis de feiras livres, 0,11 a 0,98 para os méis de supermercados e 0,15 a $1,05 \%$ para méis comercializados por produtores. Santos et al. (2010) também verificaram índice de reprovação de todas as amostras de méis analisadas da cidade de Tabuleiro do Norte, CE. O teor de sólidos insolúveis em água em méis é considerado no controle de qualidade como um índice de pureza. Estes resultados podem estar associados à não decantação e/ou filtração no final do processo de retirada do mel.
Em relação ao teor de cinzas todos os méis comercializados obtiveram o valor médio dentro do limite exigido pela legislação, não havendo diferença estatística entre elas, entretanto, observou-se que duas amostras em cada meio de comercialização apresentaram resultados acima do estabelecido pela legislação para o parâmetro de cinzas, não atendendo as exigências da legislação vigente (Brasil, 2000) que é de no máximo 0,6\%. O maior teor de cinzas foi encontrado na amostra 5 comercializada por produtores. De acordo com Venturini, Sarcinelli e Silva (2007), o teor de cinzas é influenciado pela origem botânica da flor, expressando a riqueza do mel em minerais, entretanto, o teor de cinzas muito alto indica que o mel sofreu adulterações.

$\mathrm{Na}$ reação de Lund, todas as amostras apresentaram resultado positivo indicando a presença de substâncias albuminóides, componentes normais no mel e que são 
precipitados pelo ácido tânico adicionado na amostra.

Constatou-se ainda que, para a atividade diastásica, todas as amostras encontram-se com valores dentro do permitido pela norma vigente. Segundo White Júnior (1992), os méis produzidos em regiões quentes e secas apresentam menor quantidade de enzimas do que os de regiões quentes e úmidas. White Júnior (1994) questionou o uso da atividade diastásica como indicadora de qualidade do mel devido à grande variação na quantidade de diastase em méis recém-coletados e não aquecidos. Este é um dos parâmetros que merece uma atenção especial por parte dos pesquisadores para verificar a possibilidade de adequar as normas às nossas condições.

Para a reação de Lugol, uma amostra comercializada em feira livre apresentou resultado positivo apresentando coloração marrom avermelhada. Este resultado é indicativo de adulteração do produto com amido e dextrinas.

\section{Conclusões}

Dos méis analisados, a maioria apresentou inconformidades nos tipos de embalagens utilizadas para armazenamento. Contudo, quanto aos parâmetros microbiológicos, todas as amostras apresentaram resultados dentro dos padrões exigidos pela legislação com ausência de bolores e leveduras e coliformes totais e termotolerantes.

Do ponto de vista físico-químico, em todos os locais de comercialização alguma amostra analisada estava em desacordo com o especificado pela legislação brasileira vigente pelo menos em um dos parâmetros analisados, evidenciando a necessidade de maior atenção por parte dos produtores e comerciantes desse produto apícola. Recomenda-se que sejam aplicadas as Boas Práticas de Fabricação tanto nos apiários quanto nos entrepostos para que haja a garantia da qualidade do mel produzido e processado.

\section{Referências Bibliográficas}

ALVES, E. M; DE TOLEDO, V, A, A; MARCHINI, L, C; SEREIA, M, J; MORETI, A, C, C, C; LORENZETTI, E, R; NEVES, C, A; SANTOS, A, A Presença de coliformes, bolores e leveduras em amostras de mel orgânico de abelhas africanizadas das ilhas do alto rio Paraná. Revista Ciência Rural, v.39, n.7, 2009.

ARAÚJO, D. R.; SILVA, R. H. D.; SOUSA, J. S. Avaliação da qualidade físico-química do mel comercializado na cidade de Crato-CE. Revista de Biologia e Ciências da Terra, v.6, n.1, 2006.

BRASIL. Ministério da Agricultura. Instrução normativa $\mathrm{n}^{\circ} 11$, de 20 de outubro de 2000 . Estabelece o regulamento técnico de identidade e qualidade do mel. Diário Oficial da República Federativa do Brasil, Poder Executivo, Brasília, DF, 23 out. 2000. Seção 1, p. $16-17$.

CODEX ALIMENTARIUS. Revised codex standard for honey. Rev. 2 [2001]. 24th Session of the Codex Alimentarius in 2001. Disponível em: www.condexalimentarius.net/standard. Acesso em: 20 setembro 2014.

DAYRELL, I. O.; VITAL, N. C. Comparação entre dois métodos oficiais para determinação de hidroximetilfurfural (HMF) em mel brasileiro. Ciência e Tecnologia de Alimentos, v.11, n.1, p.137-141, 1991.

DIAS, J. S.; CAMARGO, A, C.; BARIN, C. S.; E, R. M. Caracterização físico química de amostras de méis. UNOPAR Cient. Exatas Tecnol., v. 8, n. 1, p. 19-22, 2009.

INSTITUTO ADOLFO LUTZ. Normas analíticas: métodos químicos e físicos para análise de alimentos. São Paulo, 2008. 1020 p.

KOMATSU, S. S.; MARCHINI, L. C.; MORETI, A. C. C. C. Análises físico químicas de amostras de méis de flores silvestres, de eucalipto e de laranjeira, produzidos por Apis 
mellifera L., 1758 (Hymenoptera, apidae) no Estado de São Paulo. 2. Conteúdo de açúcares e de proteína. Ciencia Tecnol Alime, v. 22, p. 143-146, 2002.

LANARA - Laboratório Nacional de Referencia Animal. Métodos analíticos oficiais para controle de produtos de origem animal e seus ingredientes: II - métodos físicos e químicos. Brasília: Ministério da Agricultura, 1981.

LEAL, V.M.; SILVA, M.H.; JESUS, N.M. Aspecto físico químico do mel de abelhas comercializado no município de SalvadorBahia. Rev. Bras. Saúde Prod. An., v.1, n.1, p.14-18, 2001.

LIEVEN, M.; CORREIA, K. R.; FLOR, T. L.; FORTUNA, J. L. Avaliação da qualidade microbiológica do mel comercializado no extremo sul da Bahia. Revista Baiana de Saúde Pública, v 33: 544-552, 2009.

MOREIRA, R. F. A.; DE MARIA, C. A. B. Glicídios no mel. Química Nova, v.24, n.4, 516-525, 2001.

RODRIGUES, A. E.; SILVA, E. M. S.; BESERRA, E. M. F.; RODRIGUES, M. L. Análise físico-química dos méis das abelhas Apis mellifera e Melipona scutellaris produzidos em duas regiões no Estado da Paraíba. Ciência Rural, v35, n.5, p.1166-1171, 2005.

SANTOS, D. C.; MOURA NETO, L. G.; MARTINS, J. N.; SILVA, K. F. N. L. Avaliação da qualidade físico-química de amostras de méis comercializadas na região do Vale do Jaguaribe-CE. Revista Verde de Agroecologia e Desenvolvimento Sustentável, v.4, n.4, p. 21-26, 2009.

SANTOS, D. C.; MARTINS, J. N.; SILVA, K. F. N. L. Aspectos físico-químicos e microbiológicos do mel comercializado na cidade de Tabuleiro do Norte-Ceará. Revista Verde de Agroecologia e Desenvolvimento Sustentável, v.5, n.1, p.79-85, 2010.
SANTOS, D. C.; MOURA NETO, L. G.; MARTINS, J. N.; SILVA, K. F. N. L. Qualidade microbiológica de méis comercializados na região do Vale do Jaguaribe-CE. Revista Higiene Alimentar, v 25: 143-146, 2011 a.

SANTOS, D. C.; OLIVEIRA, E. N. A.; MARTINS, J. N.; ALBUQUERQUE, E. M. B. Qualidade físico química e microbiológica do mel de Apis mellifera comercializado na cidade de Russas, CE. Tecnologia \& Ciência Agropecuária 5: 41-45, $2011 \mathrm{~b}$.

SCHLABITZ, C.; SILVA, S. A. F.; SOUZA, C. F. V. Avaliação de parâmetros físicoquímicos e microbiológicos em mel. Revista Brasileira de Tecnologia Agroindustrial, v 4: 80-90, 2010.

SILVA, K. F. N. L. Caracterização de méis do baixo Jaguaribe - CE, 2005. $160 \mathrm{f}$. Dissertação (Mestrado em Engenharia Agrícola) - Universidade Federal de Campina Grande, Campina Grande, PB, 2005.

SILVA, M. B. L.; CHAVES, J. B. P.; MESSAGE, D.; GOMES, J. C.; GONÇALVES, M. M. OLIVEIRA, G. L. Qualidade microbiológica de méis produzidos por pequenos apicultores e de méis de entrepostos registrados no serviço de inspeção federal no estado de minas gerais. Alimentos e Nutrição, v.19, n.4, p. 417-420, 2008.

SODRÉ, G. S.; MARCHINI, L. C.; ROSA, V. P.; MORETI, A. C. C. C.; CARVALHO, C. A. L. Conteúdo microbiológico de méis de Apis mellifera (Hymenoptera: Apidae) dos estados do Ceará e Piauí. Boletim Indústrial Animal, N. Odessa, v.64, n.1, p.39-42, 2007.

VENTURINI, K. S.; SARCINELLI, M. F.; SILVA, L. C. Características do Mel. Boletim Técnico - PIE-UFES. 2007. Disponível em: http://www.agais.com/telomc/b01107. Acesso em: 22 setembro 2014.

WHITE JÚNIOR, J. W. Quality evaluation of honey: role of HMF and diastase assays. Part 
(ALVES et al., 2015)

II. American Bee Journal, v.132, n.12, p.792- WHITE JÚNIOR, J. W. The role of HMF and 794, 1992. diastase assays in honey quality evaluation. Bee World, v.75, n.3, p.104-107, 1994. 